\title{
Acute ascending polyradiculoneuritis in a case of Creutzfeldt-Jakob disease
}

\author{
E. SÁENZ LOPE ${ }^{1}$, S. RAMÓN Y CAJAL JUNQUERA, A. MARTINEZ MARTINEZ, \\ AND A. BLANES BERENGUEL
}

From the Hospital Clínico de San Carlos, Servicios de Neurología y Neuropatologia, Universidad Complutense de Madrid, Spain

SUMMARY A patient is described who showed subacute dementia and ataxia and, finally, acute ascending polyradiculoneuritis. At necropsy, together with the cerebral and cerebellar lesions that are typical of Creutzfeldt-Jakob disease, the lesions of the spinal motor neurones, the spinal ganglia, and of the roots and peripheral nerves were analogous with those of the Guillain-Barré-Landry syndrome. The aetiological possibility is discussed either that this is a simple and unique association, or that the disorder is related to the virus nature of Creutzfeldt-Jakob disease.

Creutzfeldt-Jakob disease is a progressive slow viral disorder in man caused by a transmissible agent whose precise nature remains obscure, as is the case with kuru in man, scrapie in sheep and goats, and mink encephalopathy, all of which are similarly subacute spongiform viral encephalopathies. The neuropathological features include spongy changes of the grey matter with neuronal loss and astroglial hyperplasia, affecting the cerebral cortex, striatum, and thalamus, with occasional degeneration of the cerebellum. According to the predominant clinical picture, Creutzfeldt-Jakob disease has been subdivided into several main types: (1) corticospinal or frontopyramidal form (spastic pseudosclerosis) with pyramidal tract involvement, and lower neurone involvement (amyotrophic type) (Davison and Rabiner, 1940; Allen et al., 1971); (2) classical corticostriatal or dyskinetic type; (3) occipitoparietal (Heidenhain) type, characterised by disorders of vision; (4) diffuse or 'transient' type with cerebral cortical, basal ganglia, thalamic, cerebellar, and spinal cord involvement; and (5) an ataxic or cerebellar variety 'beginning with cerebellar ataxic symptoms' which was added by Brownell and Oppenheimer (1965). The presence of radiculoneuritis in the course of Creutzfeldt-Jakob disease has not been described (Kirschbaum, 1968; May, 1968; Van Rossum, 1968). According to Langston

\footnotetext{
'Address for correspondence: Dr. E. Sáenz Lope, Centro Nacional de Rehabilitación, Jefe de Sección de Neurologia, c/ Francisco Silvela no 40, Madrid 6, Spain.

Accepted 13 September 1976
}

et al. (1975), the appearance of peripheral neuropathy in an encephalomyelopathy picture would exclude clinically the possibility of this disease. In our case the patient presented severe dementia with ataxia of 4.5 months evolution, and she died with an acute ascending polyradiculoneuritis.

\section{Case report}

C.S.R., a housewife aged 41 years, was hospitalised with a progressive organic dementia of three months' evolution. She did not recognise her family, and was confused, disoriented, and reiterative. Her behaviour was completely inadequate, with no emotional reactivity. She was uncooperative and had highly defective mnestic functions. Her speech became unintelligible, finally resulting in mutism. There was progressive instability in her gait from the beginning. Faecal and urinary incontinence arose during her stay in hospital. There were no previous familial or personal data of clinical interest.

Examination revealed a blood pressure of $150 / 90$ $\mathrm{mmHg}$, heart rate of 100 beats/min, and tachypnoea. There was a marked ataxia when upright and in walking, which she could do only with support. There was a moderate lateral nystagmus and a certain limitation in reaching the extreme ocular positions. The limb reflexes were brisk and symmetrical.

A thorough analytic study, radiology of the thorax, abdomen, and skull, and descending pyelography, revealed a urinary infection due to $E$. coli and Proteus, and this was suitably treated. An echo- 
encephalogram was normal, and two EEGs carried out in the first month of study were normal. The lumbar CSF had a protein level of $0.56 \mathrm{~g} / \mathrm{l}$, negative for globulins; there were no cells. The CSF chlorides and glucose were normal and the gamma globulin value was $0.47 \mathrm{~g} / \mathrm{l}$. Gas encephalography showed moderate dilatation of the cortical sulci. A cerebral biopsy was performed, and will be reported below.

An acute postoperative pulmonary disorder required further antibiotic treatment and intensive therapy. During the following days, the lower limbs became weak, beginning distally and quickly reaching the point of absolute flaccid tetraplegia, with large, diffuse amyotrophies and complete arreflexia. No fasciculations or alterations of the cranial nerves were observed, and the dementia did not undergo any change. A seven-day course of treatment with dexamethasone intramuscularly did not bring about any improvement. The lumbar CSF continued to have three cells per $\mathrm{ml}$, with a protein value of $0.62 \mathrm{~g} / \mathrm{l}$. The patient died as a result of cardiopulmonary complications after 48 days in hospital, 12 days after the beginning of the peripheral paralysis.

\section{Neuropathological findings}

The cerebral biopsy sample of the right frontal lobe revealed grey matter with intact structure and without neuronal loss or spongiosis. The white matter showed a low degree of astrocytic proliferation. Electron microscopy revealed focal cavitations of the neuropil due to vacuolation of some neurones and of their prolongations. The cavities were surrounded by a cellular membrane, and contained remains of nerve filaments and ribosomes (Fig. 1).

At necropsy there was a moderate degree of cortical atrophy with an increased subarachnoid space. The main arteries were free of arteriosclerosis.

The frontal cortex had the same normal appearance as in the biopsy sample. There were a large number of lesions in the parietal region, with a marked spongiosis and vacuolation of the neuropil in layers II and III. The neurones were degenerated in those zones, and there was a large gliosis with hypertrophic astrocytes (Figs. 2 and 3). The neurones were swollen in layers V and VI, with acidophilic cytoplasm, chromatolysis, and displaced nuclei. The subcortical white matter was normal. There was an obvious subependymal gliosis in the temporal cortex. The occipital region was normal.

There was a moderate spongiosis in the thalamus, which was more intense in the subependymal zones and included reactive gliosis. There were many deposits of lipofuscin in the neurones of the basal ganglia. A loss of Nissl's bodies was observed in the pontine nuclei. The long tracts of the brain stem showed no alterations.

There was marked focal loss of Purkinje's cells in the laminae cerebelli, with retraction, chromatolysis, nuclear pyknosis, and reactive gliosis. There was also marked atrophy of the granular layer (Fig. 4). At all levels of the spinal cord, and particularly in the cervical and lumbar enlargements, the neurones of the anterior horn showed intense central chromatolysis due to axonal injury (Fig. 5A). There was intense demyelination without infiltrations in the nerve roots (Fig. 5B). The spinal ganglia showed severe injuries from chromatolysis and neuronal destruction. There were inflammatory infiltrations of macrophages and lymphocytes around the degenerated neurones (Fig. 6). The demyelination was quite intense. Skeletal muscle showed extensive, severe denervation atrophy. The intramuscular nerves had undergone degenerative changes with complete demyelination (Fig. 7). Visceral examination revealed haemorrhagic gastritis and pulmonary oedema with many foci of bronchopneumonia.

\section{SUMMARY OF NEUROPATHOLOGY}

The biopsy specimen of the frontal lobe showed alterations only on the ultrastructural level, with $\frac{\vec{b}}{0}$ vacuolation of the neuropil due to dilatation of the 을 neuronal prolongations (Brion et al., 1969). The spongiosis and gliosis lesions of the cerebral cortex and basal nuclei were much more pronounced in the $\frac{0}{2}$ parietotemporal region, with characteristics thato ฏ were similar to those described by Brownell and Oppenheimer (1965) and Gomori et al. (1973) ing $\overrightarrow{0}$ Creutzfeldt-Jakob disease. We did not find any $\forall$ argyrophilic plaques or neurofibrillar degeneration as described by Hirano et al. (1972).

Fifty per cent of the cases of Creutzfeldt-Jakob disease suffer from cerebellar lesions, and axonal torpedos and plates resembling those found in kuru (Jellinger et al., 1974) are also frequent in the ataxic form of this illness, although we did not observe any of these in our patient. The severe lesions of the neurones of the anterior horn and of the spinal ganglia in the form of central chromatolysis were the expression, in our case, of the severe involvement of the nerve roots and peripheral nerves, which was the basis of the acute polyradiculoneuritis shown by the patient during life. Demyelination was the most prominent feature in the roots, and there were also inflammatory infiltrations in the spinal ganglia.

\section{Discussion}

We have found no mention of the association of Creutzfeldt-Jakob disease with peripheral neuropathies and acute polyradiculoneuritis in long published series of polyneuropathy (Ravn, 1967; 


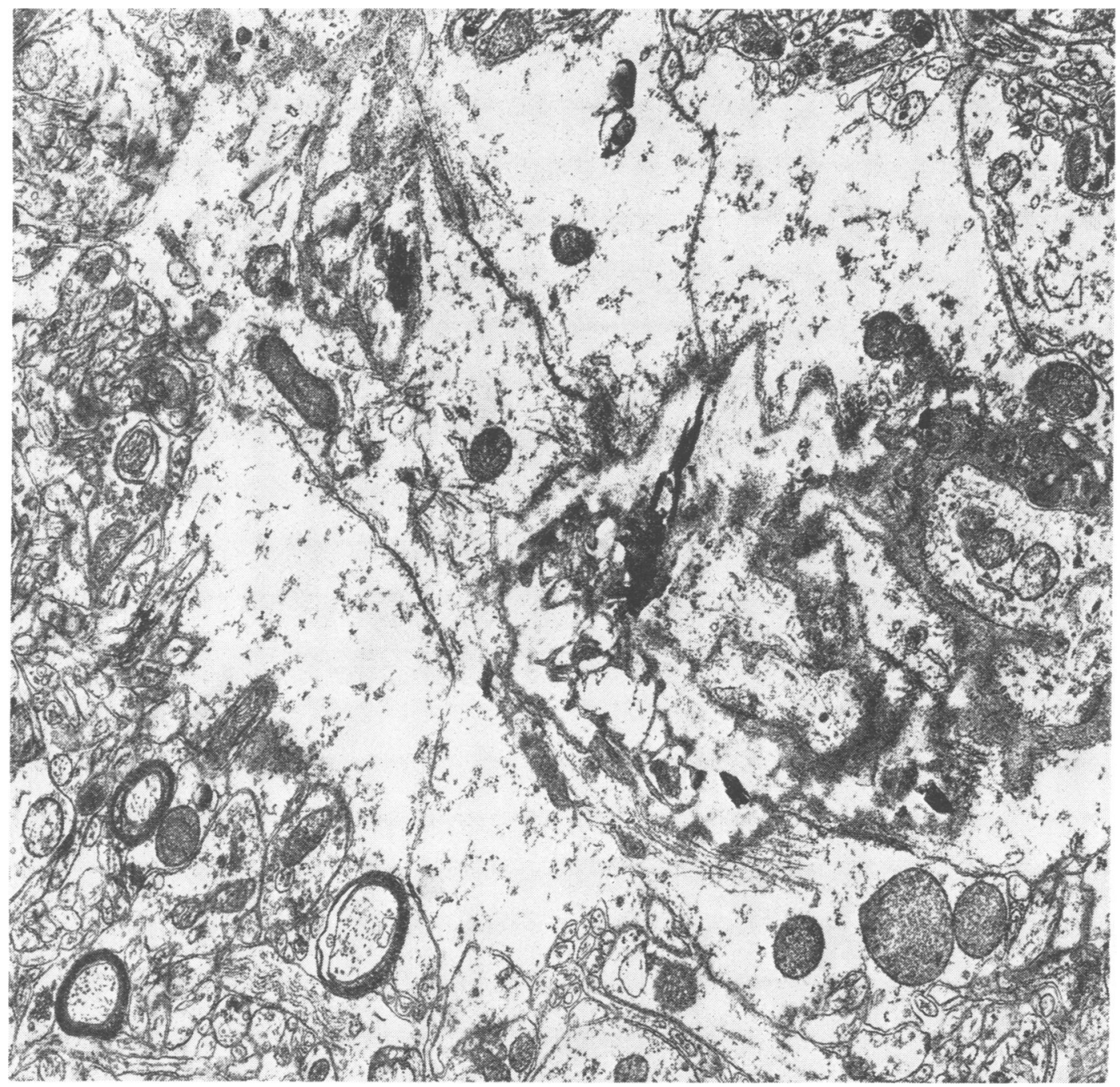

Fig. 1 Grey matter of frontal lobe. Vacuolation of the neuropil. $\times 5700$.

Bradley, 1975; Freemon, 1975). Acute polyradiculoneuritis frequently arises after different types of infections and after surgical operations, including intracranial ones, in 5 to $10 \%$ of the cases. In our patient, a urinary infection preceded the cerebral biopsy and the posterior pneumonia. From this standpoint, the polyradiculoneuritis and the Creutzfeldt-Jakob disease would be a simple and, so far, unique association, although the origin of the latter allows other pathogenic considerations.

Many encephalopathies and encephalomyelopathies have been described in which a peripheral neuropathy appears, sometimes with an acute onset.
The aetiology is quite varied, sometimes being of an obscure nature as in cases 30 and 31 of Prineas (1970), and in the case of Langston et al. (1975). Cases associated with a habitually malignant systemic illness are most frequent (Croft et al., 1967; Vick et al., 1969; McLeod, 1975). Others are associated with different immunological disorders (McLeod and Walsh, 1975a,b; Sponzilli et al., 1975). Lastly, some cases are associated with encephalopathies of a proven virus nature (Faris and Martinez, 1972; Narayan et al., 1973).

It is obvious that virus infection and alteration of immune responses, in isolated or interdependent 


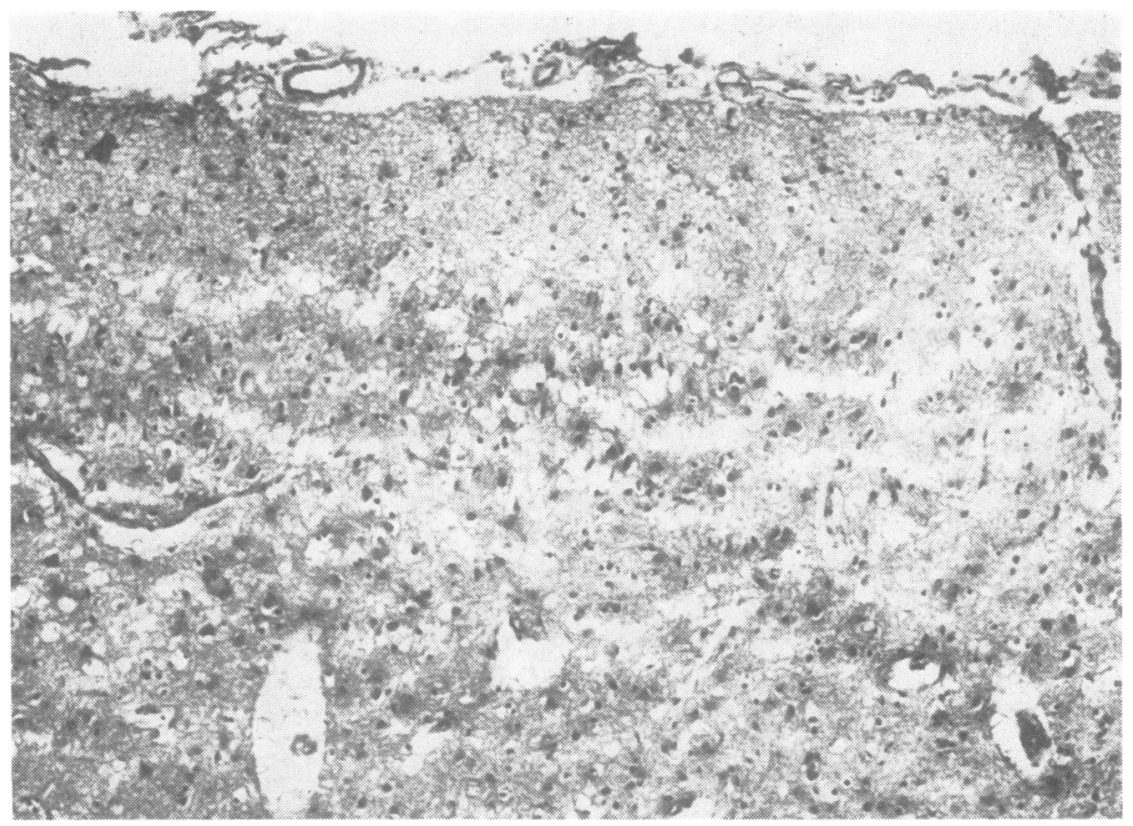

Fig. 2 Parietal cortex. Spongiosis in layers II and III. $H$ and $E$, $\times 300$.

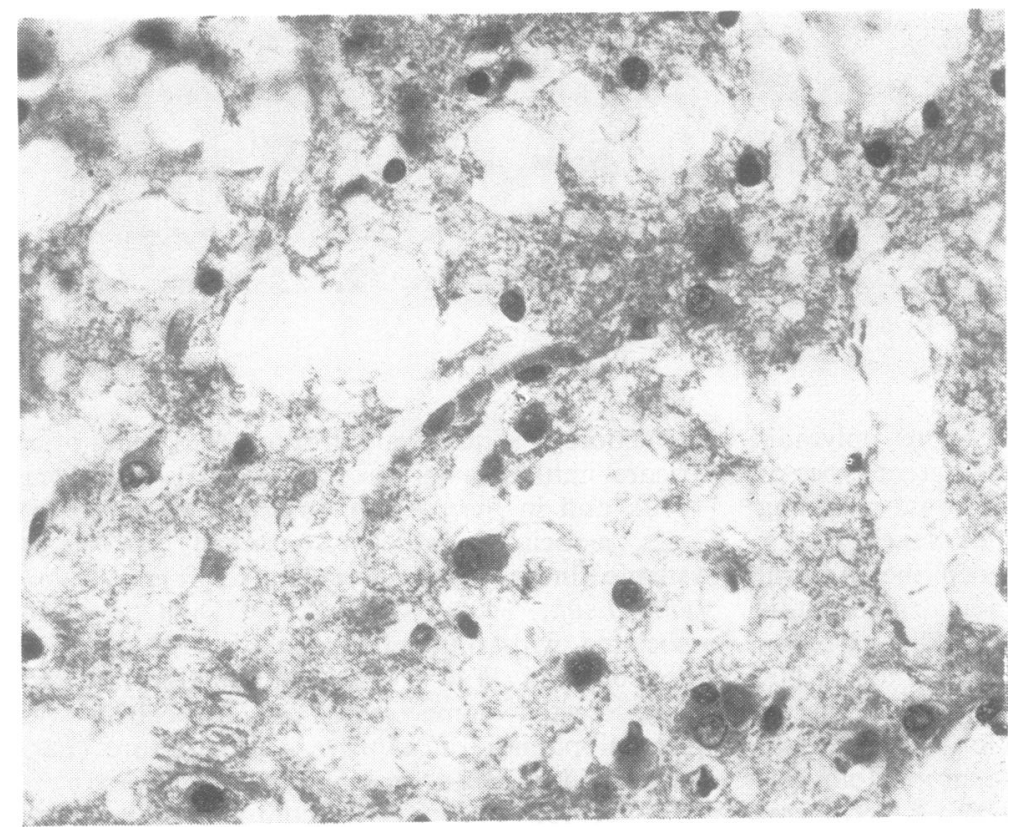

Fig. 3 Spongiosis, neuronal necrosis, and reactive gliosis in the parietal cortex. $H$ and $E$, $\times 500$. 


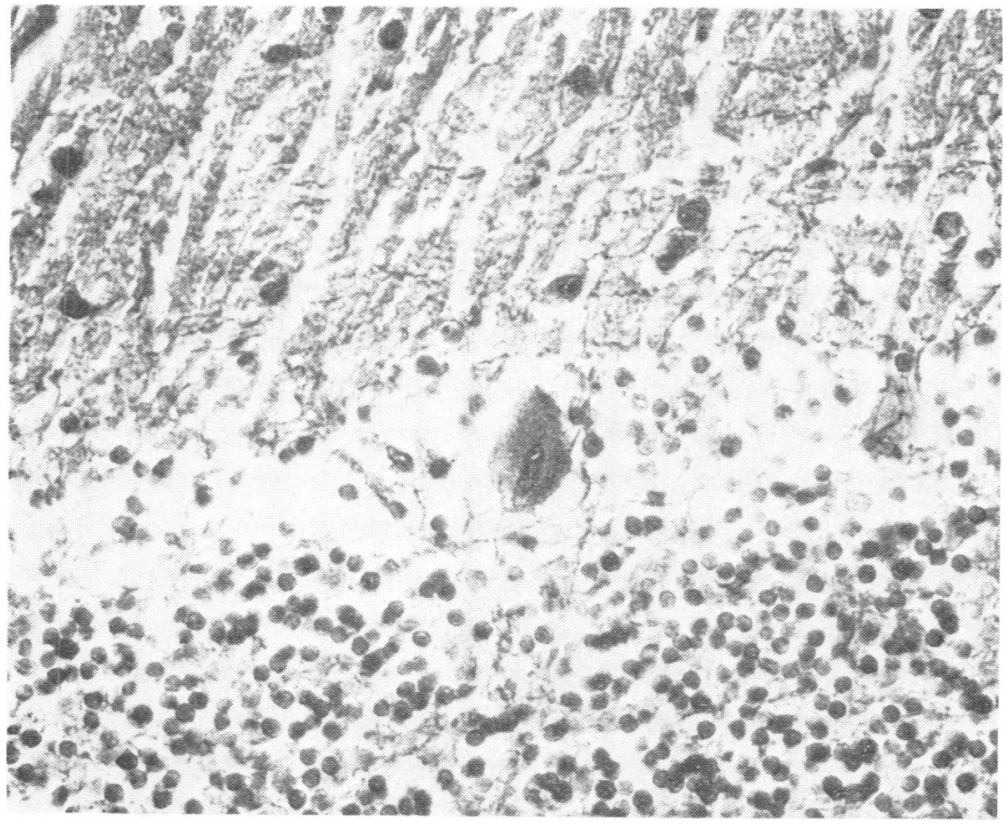

Fig. 4 Cerebellum. Loss of Purkinje's cells and atrophy in the granular layer. Giess, $\times 800$.

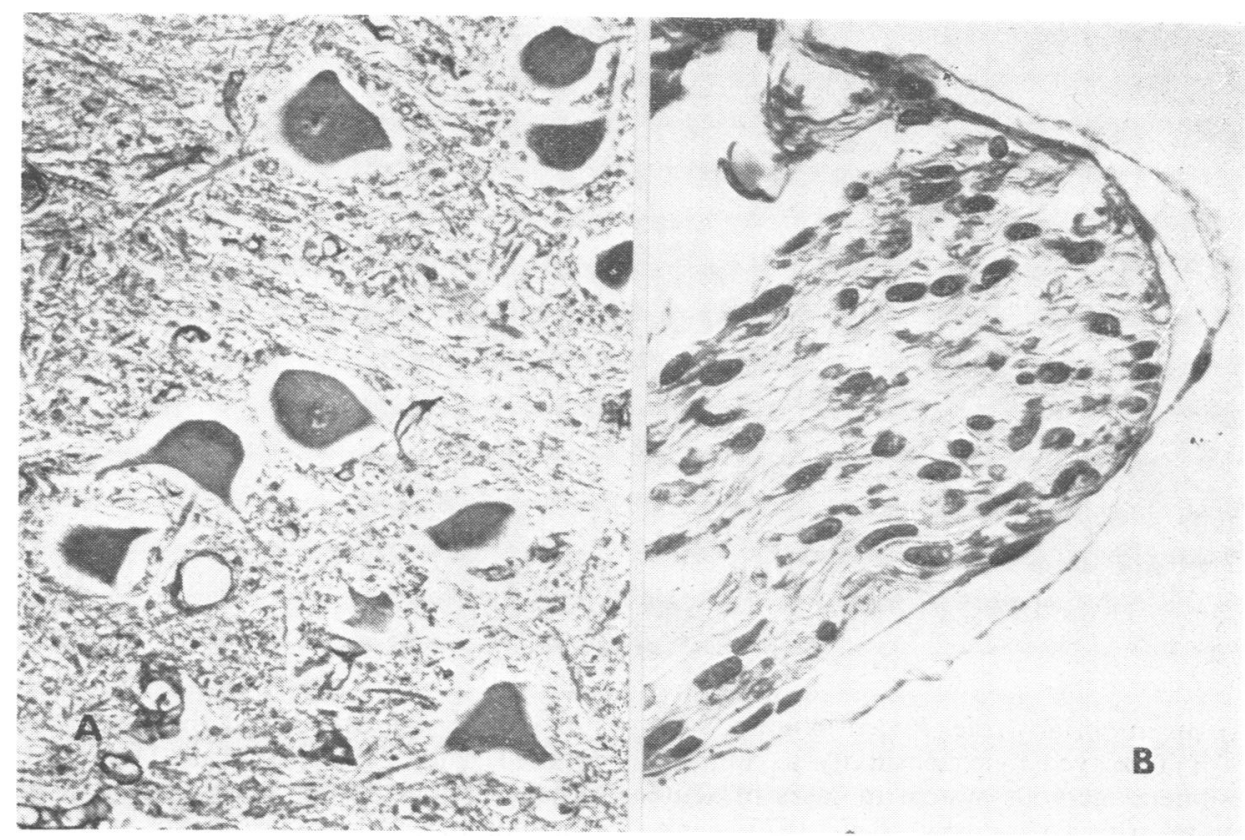

Fig. 5 A. Thoracic cord. Central chromatolysis due to axonal injury. B. Thoracic root with complete demyelination. Lendrum, $\times 800$. 


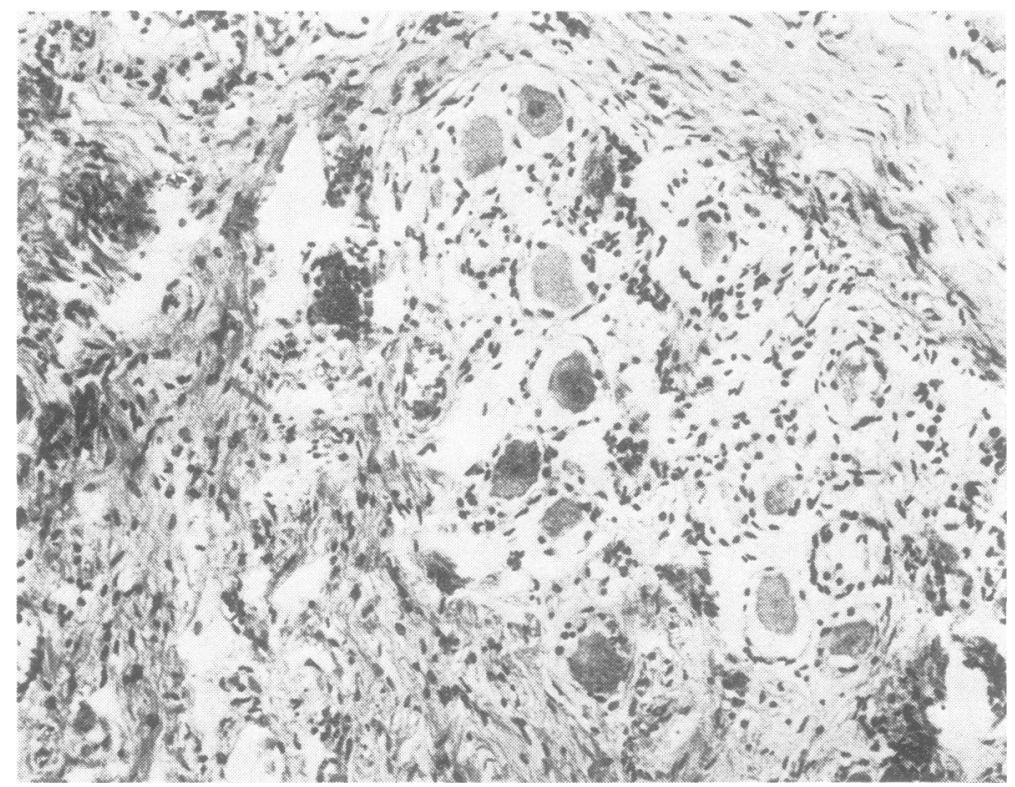

Fig. 6 Spinal ganglion. Central chromatolysis and neuronal degeneration. Inflammatory infiltrations of lymphocytes and macrophages. $H$ and $E, \times 200$.

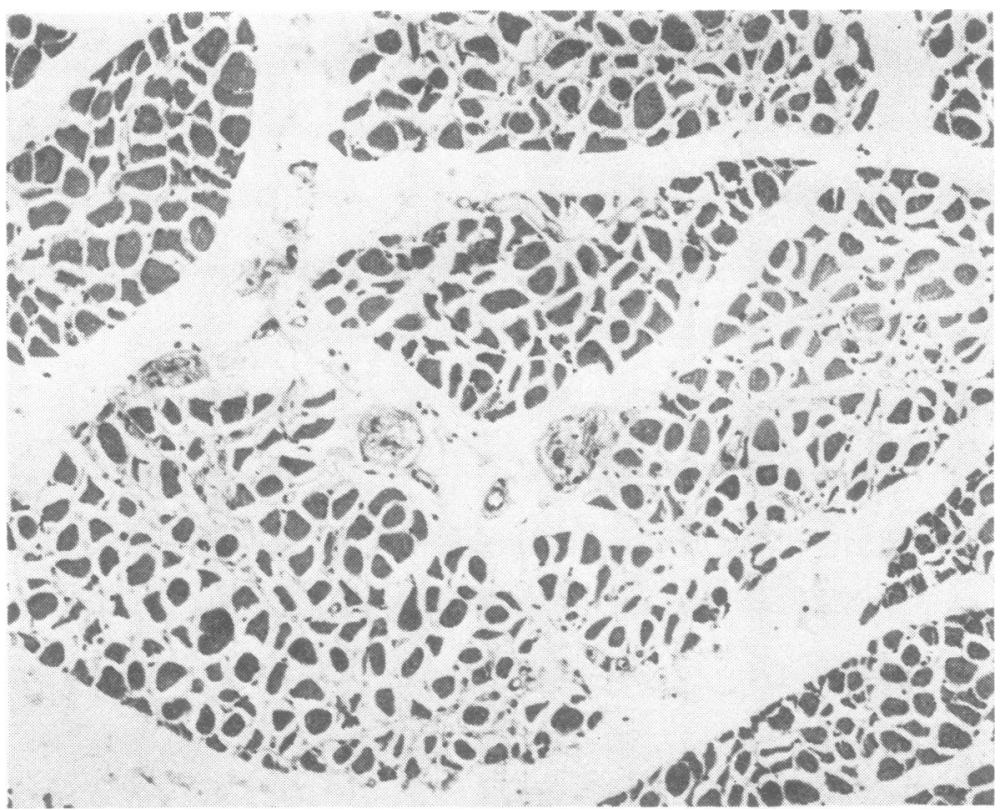

Fig. 7 Atrophy of muscle due to denervation and degeneration of the intramuscular nerve bundles. $H$ and $E, \times 300$.

form, play an important role. Recent studies show that there is a delayed hypersensitivity to antigens of the peripheral nervous system in cases of acute polyradiculoneuritis (Abramsky et al., 1975; Link, 1975; Sheremata et al., 1975), in which a virus infection could have a special significance (Arnason, 1975).
It is now well established that Creutzfeldt-Jakob disease is caused by a slow virus. This agent has been successfully transmitted in experiments, although its exact nature is still obscure (Gibbs et al., 1968; Roos et al., 1973). Although in our case we did not attempt to transmit the illness to laboratory animals, the clinical and pathological picture left little doubt as 
to the viral aetiology of the process. It is interesting to consider the possibility that the same virus agent in our case was capable of producing the brain lesions which determined the subacute dementia and ataxia, and, either directly or by means of altered immunological mechanisms, may have damaged the roots and the peripheral nerves.

\section{References}

Abramsky, D., Webb, C., Teitelbaum, D., and Arnon, R. (1975). Cell-mediated immunity to neural antigens in idiopathic polyneuritis and myeloradiculitis. Neurology (Minneap.), 25, 1154-1159.

Allen, I. V., Dermott, E., Conolly, J. H., and Hurwitz, L. J. (1971). A study of a patient with the amyotrophic form of Creutzfeldt-Jakob disease. Brain, 94, 715-724.

Arnason, B. G. W. (1975). Inflammatory polyradiculoneuropathies. In Peripheral Neuropathy, pp. 11001184. Edited by P. J. Dyck, P. K. Thomas, and E. H. Lambert. Saunders: Philadelphia.

Bradley, W. G. (1975). Disorders of the Peripheral Nerves, pp. 177-180. Blackwell: Oxford.

Brion, S., Mikol, J., Raverdy, P., and Isidor, P. (1969). Etude anatomo-clinique d'un cas de maladie de Creutzfeldt-Jakob-Aspects ultra-structuraux. Revue Neurologique, 121, 2, 165-179.

Brownell, B., and Oppenheimer, D. R. (1965). An ataxic form of subacute presenile polioencephalopathy (Creutzfeldt-Jakob disease). Journal of Neurology, Neurosurgery, and Psychiatry, 28, 350-361.

Croft, P. B., Urich, H., and Wilkinson, M. (1967). Peripheral neuropathy of sensorimotor type associated with malignant disease. Brain, 90, 31-66.

Davison, C., and Rabiner, A. M. (1940). Spastic pseudosclerosis (disseminated encephalomyelopathy; corticopallidospinal degeneration). Archives of Neurology and Psychiatry, 44, 578-598.

Faris, A. A., and Martinez, A. J. (1972). Primary progressive multifocal leukoencephalopathy. A central nervous system disease caused by a slow virus. Archives of Neurology (Chic.), 27, 357-360.

Freeman, F. R. (1975). Causes of polyneuropathy. Acta Neurologica Scandinavica, suppl. 59, vol. 51.

Gibbs, C. J. Jr, Gajdusek, D. C., Asher, D. M., Alpers, M. P., Beck, E., Daniel, P. M., and Matthews, W. B. (1968). Creutzfeldt-Jakob disease (spongiform encephalopathy): transmission to the chimpanzee. Science N.Y., 161, 388-389.

Gomori, A. J., Partnow, M. J., Horoupian, D. S., and Hirano, A. (1973). The ataxic form of Creutzfeldt-Jakob disease. Archives of Neurology (Chic.), 29, 316-323.

Hirano, A., Ghatak, N. R., Johnson, A. B., Partnow, M. J., and Gomori, A. J. (1972). Argentophilic plaques in Creutzfeldt-Jakob disease. Archives of Neurology (Chic.), 26, 530-542.

Jellinger, K. W., Heiss, D., and Deisenhammer, E. (1974).
The ataxic (cerebellar) form of Creutzfeldt-Jakob disease. Journal of Neurology, 207, 289-305.

Kirschbaum, W. R. (1968). Jakob-Creutzfeldt Disease. American Elsevier: New York.

Langston, J. W., Dorffman, L. J., and Forno, L. S. (1975). 'Encephalomyeloneuritis' in the absence of cancer. Neurology (Minneap.), 25, 633-637.

Link, H. (1975). Demonstration of oligoclonal immunoglobulin $\mathrm{G}$ in Guillain-Barré syndrome. Acta Neurologica Scandinavica, 52, 111-120.

McLeod, J. G. (1975). Carcinomatous neuropathy. In Peripheral Neuropathy, pp. 1301-1313. Edited by P. J. Dick, P. K. Thomas, and E. H. Lambert. Saunders: Philadelphia.

McLeod, J. G., and Walsh, J. C. (1975a). Neuropathies associated with paraproteinemias and dysproteinemias. In Peripheral Neuropathy, pp. 1012-1029. Edited by P. J. Dyck, P. K. Thomas, and E. H. Lambert. Saunders: Philadelphia.

McLeod, J. G., and Walsh, J. C. (1975b). Peripheral neuropathy associated with lymphomas and other reticuloses. In Peripheral Neuropathy, pp. 1314-1325. Edited by P. J. Dyck, P. K. Thomas, and E. H. Lambert. Saunders: Philadelphia.

May, W. W. (1968). Creutzfeldt-Jakob disease: a survey of the literature and clinical diagnosis. Acta Neurologica Scandinavica, 44, 1-32.

Narayan, O., Penney, J. B. Jr, Johnson, R. T., Herndon, R. M., and Weiner, L. P. (1973). Etiology of progressive multifocal leukoencephalopathy. Identification of Papova virus. New England Journal of Medicine, 289, 1278-1282.

Prineas, J. (1970). Polyneuropathies of undetermined cause. Acta Neurologica Scandinavica, suppl. 44, vol. 46.

Ravn, H. (1967). The Landry-Guillain-Barré syndrome. A survey and clinical report of 127 cases. Acta Neurologica Scandinavica, suppl. 30, vol. 43.

Roos, R., Gajdusek, D. C., and Gibbs, C. J. Jr (1973). The clinical characteristics of transmissible CreutzfeldtJakob disease. Brain, 96, 1-20.

Sheremata, W., Colby, S., Lusky, G., and Cosgrove, J. B. R. (1975). Cellular hypersensitization to peripheral nervous antigens in the Guillain-Barré syndrome. Neurology (Minneap.), 25, 833-839.

Sponzilli, E. E., Smith, J. K., Malamud, N., and McCulloch, J. R. (1975). Progressive multifocal leukoencephalopathy: a complication of immunosuppressive treatment. Neurology (Minneap.), 25, 664668.

Van Rossum, A. (1968). Spastic pseudosclerosis (Creutzfeldt- Jakob disease). In Handbook of Clinical Neurology, vol. 6, pp. 726-760. Edited by P. J. Vinken and G. W. Bruyn. North Holland: Amsterdam.

Vick, N., Sculman, S., and Dau, P. (1969). Carcinomatous cerebellar degeneration, encephalomyelitis and sensory neuropathy (radiculitis). Neurology (Minneap.), 19, $425-441$. 